\title{
DETERMINAÇÃO SIMULTÂNEA DE CREATININA E INDICADORES BIOLÓGICOS DE EXPOSIÇÃO AO TOLUENO, ESTIRENO E XILENOS EM URINA POR CROMATOGRAFIA LÍQUIDA DE ALTA EFICIÊNCIA
}

\author{
Marina Venzon Antunes, Ana Luiza Marques Patuzzi e Rafael Linden* \\ Curso de Ciências Farmacêuticas, Instituto de Ciências da Saúde, Centro Universitário Feevale, Rodovia RS 239, 2755, 93352-000 \\ Novo Hamburgo - RS, Brasil
}

Recebido em 22/10/07; aceito em 29/2/08; publicado na web em 22/9/08

\begin{abstract}
SIMULTANEOUS DETERMINATION OF CREATININE AND BIOLOGICAL INDICATORS OF EXPOSURE TO TOLUENE, STYRENE AND XYLENES IN URINE BY HIGH PERFORMANCE LIQUID CHROMATOGRAPHY. A simple liquid chromatographic method for the simultaneous determination of creatinine, hippuric acid, mandelic acid, phenylglyoxylic acid and $o, m$ and $p$-methylhippuric acids was developed and validated. Sample preparation was only dilution with water (1:10), followed by centrifugation. Analysis was performed in a reversed phase column (Lichrospher RP 8ec), 250 x $4.0 \mathrm{~mm}$, with isocratic elution with phosphate buffer $\mathrm{pH} 2.3$ and acetonitrile $(90: 10, \mathrm{v} / \mathrm{v})$. The method presents adequate linearity, precision and accuracy and allows the simultaneous determination of the biomarkers of exposure to toluene, xylene and styrene together with creatinine, reducing cost and laboratory time.
\end{abstract}

Keywords: HPLC-DAD; organic solvent exposure; biological monitoring.

\section{INTRODUÇÃO}

Os compostos orgânicos aromáticos tolueno, xileno e estireno apresentam ampla aplicabilidade em diversos segmentos industriais, tais como a produção de componentes para indústrias de tintas, plásticos, farmacêutica, pesticidas, borracha e de preparações comerciais diversas. ${ }^{1,2}$ A exposição a estes agentes químicos pode levar a diversos efeitos tóxicos importantes, sendo recomendado o monitoramento biológico dos indivíduos expostos ocupacionalmente. Usualmente, a avaliação da exposição é realizada através da determinação quantitativa de seus metabólitos excretados na urina, a qual apresenta uma boa relação com o nível de exposição. ${ }^{3-5}$

No Brasil, a Norma Regulamentadora $n^{\circ} 7$ (NR-7) do Ministério do Trabalho e Emprego, que instituiu o Programa de Controle Médico de Saúde Ocupacional, estabelece a obrigatoriedade, por parte das empresas e instituições que possuam trabalhadores expostos a tolueno, xileno e estireno, do monitoramento biológico periódico destes trabalhadores. ${ }^{6}$ A NR-7 indica a determinação, em amostras de urina de final de jornada, do ácido hipúrico (AH) como indicador de exposição ao tolueno, dos ácidos metil-hipúricos (AMH) como indicadores de exposição ao xileno e dos ácidos mandélico (AM) e fenilglioxílico (AFG) como indicadores de exposição ao estireno (Figura 1). Os valores de referência e os índices biológicos máximos permitidos, representados como gramas do metabólito por grama de creatinina (CR), estão apresentados na Tabela 1 . A relação com a concentração da creatinina urinária é utilizada para compensar as variações na excreção renal, que podem impactar nos valores absolutos de concentração dos indicadores de exposição. Usualmente, a creatinina é determinada por métodos colorimétricos, em procedimento paralelo à determinação dos indicadores biológicos de exposição por técnicas cromatográficas.

Existem relatos na literatura da determinação, em amostras de urina, de AH, AMH, AM e AFG em diferentes combinações, tanto por cromatografia gasosa quanto líquida de alta eficiência..$^{1,7-12}$ Entretanto, nenhum método incorpora todos estes analitos conjuntamente

*e-mail: rafael.linden@feevale.br<smiles>CN1CC(=O)NC1=N</smiles>

Creatinina<smiles>O=C(O)CNC(=O)c1ccccc1</smiles>

Ácido hipúrico<smiles>O=C(O)C(O)c1ccccc1</smiles>

Ácido mandélico<smiles>O=C(O)C(=O)c1ccccc1</smiles>

Ácido fenil-glioxílico<smiles>Cc1ccccc1C(=O)NCC(=O)O</smiles>

Ácido o-metil-hipúrico
Figura 1. Estrutura química da creatinina e dos indicadores biológicos de exposição a tolueno, estireno e xilenos (representado apenas o isômero orto do $A M H)$

com a determinação de CR. Desta forma, a análise simultânea destes analitos, especialmente com a utilização de uma metodologia simples e rápida de preparação de amostra, pode representar um importante ganho em produtividade e redução de custos.

O presente trabalho descreve um método simples de cromatografia líquida de alta eficiência em fase reversa com detector de arranjo de diodos (CLAE-DAD) para a determinação simultânea de ácido hipúrico, ácido mandélico, ácido fenilglioxílico, ácidos metil-hipúricos e creatinina em amostras de urina, com uma preparação de amostra simples e separação isocrática, para monitoramento biológico da exposição a tolueno, xileno e estireno.

\section{PARTE EXPERIMENTAL}

\section{Reagentes}

Padrões de referência de ácido metil-hipúrico (orto, meta e para), ácido mandélico e ácido fenilglioxílico foram obtidos da Sigma Aldrich (Saint Louis, EUA). Ácido hipúrico foi adquirido 
Tabela 1. Indicadores biológicos de exposição ao tolueno, xileno e estireno ${ }^{4}$

\begin{tabular}{|c|c|c|c|c|}
\hline Solvente & Amostra & Indicador biológico & Valor de referência & IBMP \\
\hline Tolueno & Urina & Ácido hipúrico & Até $1,5 \mathrm{~g} / \mathrm{g}$ de creatinina & $2,50 \mathrm{~g} / \mathrm{g}$ de creatinina \\
\hline Xilenos & Urina & Ácidos metil-hipúricos & n.d. & $1,50 \mathrm{~g} / \mathrm{g}$ de creatinina \\
\hline \multirow{2}{*}{ Estireno } & \multirow{2}{*}{ Urina } & Ácido mandélico & n.d. & $0,80 \mathrm{~g} / \mathrm{g}$ de creatinina \\
\hline & & Ácido fenil-glioxílico & n.d. & $0,24 \mathrm{~g} / \mathrm{g}$ de creatinina \\
\hline
\end{tabular}

IBMP: Indicador Biológico Máximo Permitido; n.d.: não disponível

da Acros Organics (Geel, Bélgica). Acetonitrila grau HPLC foi da Merck (Darmstadt, Alemanha). Água purificada foi obtida através de um sistema Elga Purelab Ultra da Elga Labwater (Lane End, Reino Unido). A solução calibradora de creatinina foi obtida da Labtest (Lagoa Santa, Brasil).

\section{Equipamentos}

Foi utilizado um cromatógrafo líquido de alta eficiência Shimadzu Class VP (Kioto, Japão), composto de um sistema quaternário de bombas LC-10AT, módulo controlador SCL-10A, desgaseificador DGV-14A, forno de coluna CTO-10AS, auto-injetor SIL-10AF e detector de arranjo de diodos SPD-M10A. A coluna utilizada foi LiChrospher ${ }^{\circledast}$ RP 8 ec $(250$ X 4 mm, d.p. $5 \mu \mathrm{m})$ da Merck (Darmstadt, Alemanha). O sistema de cromatografia foi controlado pelo programa Class VP 6.13 SP2, da Shimadzu.

\section{Preparação da fase móvel e condições cromatográficas}

A fase móvel foi preparada através da mistura de tampão fosfato pH $2.3(50 \mathrm{mM})$ e acetonitrila (90:10, v/v). O tampão fosfato foi preparado através da dissolução de 6,66 g de fosfato de potássio monobásico em $800 \mathrm{~mL}$ de água purificada, seguida da adição de $4,8 \mathrm{~g}$ de ácido fosfórico $85 \%$ (v/v). O volume foi completado para $1000 \mathrm{~mL}$ com água purificada e o pH foi ajustado com a adição de ácido fosfórico ou hidróxido de potássio 0,1 M. Antes da utilização, a fase móvel foi filtrada através de membrana de acetato de celulose com poros de 0,45 $\mu \mathrm{m}$ (Sartorius, Alemanha) e desgaseificada em banho ultra-sônico por $5 \mathrm{~min}$. O fluxo da fase móvel foi de 1,2 $\mathrm{mL} /$ min. A coluna foi mantida a $30{ }^{\circ} \mathrm{C}$ durante a análise. $\mathrm{O}$ volume de injeção foi de $25 \mu \mathrm{L}$. A detecção foi realizada a $225 \mathrm{~nm}$ para todos os compostos, com a aquisição de espectros de varredura entre $200 \mathrm{e}$ $380 \mathrm{~nm}$. Em cada lote de análises foi inserida uma amostra controle de concentração conhecida. A cada 10 análises, uma amostra foi processada em duplicata.

\section{Curva de calibração}

As curvas de calibração foram obtidas através da diluição com água purificada das soluções-padrão de cada um dos padrões em solução aquosa nas concentrações $400 \mu \mathrm{g} / \mathrm{mL}$ para CR; $1,5 \mathrm{mg}$ / $\mathrm{mL}$ para $\mathrm{AH}$ e AMHs; $2,2 \mathrm{mg} / \mathrm{mL}$ para AM e $2 \mathrm{mg} / \mathrm{mL}$ para AFG. Para a construção da curva de calibração, foi utilizada a média de 6 determinações de cada calibrador. Foram utilizados calibradores em 6 níveis diferentes para cada analito. A curva de calibração foi construída através do estabelecimento da correlação entre a área dos picos referentes a cada analito (y) e as concentrações adicionadas (x). A curva foi avaliada com base no coeficiente de determinação $\left(\mathrm{r}^{2}\right)$. Foram utilizados calibradores nas concentrações de 20 a $800 \mu \mathrm{g} / \mathrm{mL}$ para CR; 250 a $3000 \mu \mathrm{g} / \mathrm{mL}$ para $\mathrm{AH} ; 180$ a $1350 \mu \mathrm{g} / \mathrm{mL}$ para $\mathrm{AM}$; 360 a $2700 \mu \mathrm{g} / \mathrm{mL}$ para FG; 250 a $2000 \mu \mathrm{g} / \mathrm{mL}$ para $o-A M H$ e 250 a $2000 \mu \mathrm{g} / \mathrm{mL}$ para $m$ e $p$-AMH.

\section{Coleta e conservação das amostras}

Foram obtidas amostras de trabalhadores expostos a tolueno, xileno e estireno, nas seguintes ocupações: indústria química de tintas para calçados $(n=15)$, ateliê de pintura $(n=15)$ e maqueteria em fibra de vidro $(n=15)$, totalizando 45 amostras. Todas as amostras de urina foram coletadas no quarto dia útil da semana, no final da jornada de trabalho. Imediatamente após a coleta, as amostras foram armazenadas sob refrigeração a $4{ }^{\circ} \mathrm{C}$. As análises foram realizadas no dia seguinte à coleta.

\section{Preparo das amostras}

Uma alíquota de $100 \mu \mathrm{L}$ de urina, em microtubos de polipropileno, foi diluída com $900 \mu \mathrm{L}$ de água purificada. Esta mistura foi homogeneizada em agitador vórtex por $30 \mathrm{~s}$ e posteriormente centrifugada a $12.000 \mathrm{rpm}$ por $5 \mathrm{~min}$, à temperatura de $4{ }^{\circ} \mathrm{C}$. Uma alíquota de $25 \mu \mathrm{L}$ do sobrenadante foi injetada no sistema CLAE-DAD.

\section{Avaliação do efeito da matriz}

Um pool de amostras de urina de indivíduos não expostos a tolueno, xileno e estireno foi processado, em triplicata, segundo o procedimento descrito no ítem anterior, a fim de obter as áreas médias dos picos da creatinina e do ácido hipúrico endógenos. Alíquotas da mesma amostra de urina também foram processadas em triplicata, após a adição das seguintes concentrações dos analitos: 33 e $266 \mu \mathrm{g} /$ $\mathrm{mL}$ de CR; 600, 1800 e $2800 \mu \mathrm{g} / \mathrm{mL}$ de AH; 270, 630 e $1260 \mu \mathrm{g} / \mathrm{mL}$ de AM; 540, 1620 e $2520 \mu \mathrm{g} / \mathrm{mL}$ de FG; 600, 1600 e $2400 \mu \mathrm{g} / \mathrm{mL}$ de $o$-AMH e 600, 1600 e $2400 \mu \mathrm{g} / \mathrm{mL}$ de $m$ e $p$-AMH. A diferença entre os valores das áreas na amostra de urina antes e depois da adição dos analitos foi utilizada para o cálculo das concentrações, empregando as curvas de calibração obtidas com as soluções aquosas (ítem curva de calibração). A variação na concentração obtida com a matriz urina foi expressa como percentagem do valor estimado pela curva de calibração.

\section{Ensaios de precisão e exatidão}

A precisão e a exatidão do método foram avaliadas através de análises em três níveis de concentração para cada analito, realizadas em triplicata e repetidas em 5 dias diferentes. Os calibradores utilizados foram preparados em água purificada. A precisão intra-ensaios e a precisão inter-ensaios foram calculadas pela análise de variância (ANOVA), usando dia como variável agrupadora. A exatidão foi calculada como percentagem média obtida do valor teórico adicionado na amostra. As concentrações utilizadas no estudo de precisão e exatidão foram: 33, 266 e $720 \mu \mathrm{g} / \mathrm{mL}$ para CR; 600, 1800 e 2800 $\mu \mathrm{g} / \mathrm{mL}$ para AH; 270, 630 e $1260 \mu \mathrm{g} / \mathrm{mL}$ para AM; 540, 1620 e 2520 $\mu \mathrm{g} / \mathrm{mL}$ para FG; 600,1600 e $2400 \mu \mathrm{g} / \mathrm{mL}$ para $o-\mathrm{AMH}$ e 600,1600 e $2400 \mu \mathrm{g} / \mathrm{mL}$ para $m$ e $p$-AMH. 


\section{Limites de detecção e quantificação}

Os limites de detecção e quantificação de cada analito foram determinados a partir do cálculo da concentração de 3 e 10 vezes, respectivamente, a área do ruído da linha de base produzido pela matriz.

\section{RESULTADOS E DISCUSSÃO}

\section{Condições cromatográficas}

Com as condições cromatográficas utilizadas foi possível separar todos os analitos, com exceção dos isômeros para e meta do ácido metil-hipúrico, os quais coeluem. Além disso, não foram observados interferentes nos tempos de retenção relativos aos diferentes analitos, quando avaliados quanto à sua pureza espectral e similaridade com os espectros de absorção de referência, através de rotinas disponíveis no sistema CLAE-DAD. Empregando o valor limiar do índice de similaridade espectral de 0,995 , calculado através de rotina própria do programa Class VP, todos os analitos puderam ser diferenciados através de seus espectros de absorção entre 200 e $380 \mathrm{~nm}$. Os isômeros para e meta do ácido metil-hipúrico foram quantificados de forma aditiva, o que não representa uma limitação importante uma vez que a NR-7 determina o Índice Biológico Máximo Permitido (IBMP) para a soma dos isômeros do ácido metil-hipúrico, não sendo necessária a sua quantificação individualizada. O tempo total de análise foi de 25 min, incluindo todos os analitos. Entretanto, este tempo pode ser reduzido para cerca de $12 \mathrm{~min}$, ou menos, dependo do composto a ser determinado. Os tempos médios de retenção foram 1,9 min para CR; 5,6 min para $\mathrm{AFG} ; 9$ min para $\mathrm{AM} ; 10,5$ min para $\mathrm{AH} ; 14$ min para $o$-AMH; 23,5 min para $m$-AMH e 24,5 min para $p$-AMH. A Figura 2 apresenta cromatogramas típicos obtidos com o presente método.

No método para determinação de $\mathrm{AMHs}, \mathrm{AFG}$ e $\mathrm{AM}$, proposto por Ohashi et al., ${ }^{1}$ o preparo das amostras segue procedimentos de múltiplas extrações, sendo necessário inclusive a realização de etapa de evaporação, processos que tornam a técnica trabalhosa e demorada. $\mathrm{Na}$ metodologia proposta, a preparação de amostra utilizada, que compreende apenas uma etapa de diluição com água e centrifugação, permite análises rápidas e de baixo custo. Também, considerando a simplicidade do procedimento, foi possível obter elevada repetibilidade mesmo sem a utilização de um padrão interno, como pode ser observado pelos valores de precisão apresentados na Tabela 2 . No trabalho de Laffon et al., ${ }^{7}$ apesar das amostras também serem preparadas de forma simplificada, a técnica possibilita a análise de apenas AM e AFG. Chakroun et al. ${ }^{10}$ propuseram uma metodologia que abrange a análise de todos os bioindicadores avaliados neste trabalho, porém não inclui a determinação de creatinina. Além disso, foi empregada eluição por gradiente, ao contrário do presente método onde a eluição ocorre em condição isocrática. Neste caso, em virtude da necessidade de reequilíbrio da fase móvel para o início de nova corrida analítica, o tempo de análise foi de mais de $40 \mathrm{~min}$, além de impossibilitar a interrupção das corridas quando não há interesse em determinar todos os biomarcadores.

Considerando a presença endógena de CR e AH em urina, os calibradores foram preparados em água purificada. As curvas de calibração obtidas apresentaram linearidade adequadas, todas com valores de $\mathrm{r}^{2}$ acima de 0,995 . O efeito da matriz foi avaliado em amostras de urina provenientes de indivíduos não expostos a tolueno, xileno e estireno, processadas antes e após a adição de concentrações conhecidas dos analitos. Antes da fortificação, foram detectados apenas $\mathrm{CR}$ e AH. As áreas obtidas com as amostras de urina fortificadas, subtraídas das áreas dos picos endógenos, foram utilizadas para cálculo das concentrações adicionadas usando as curvas de
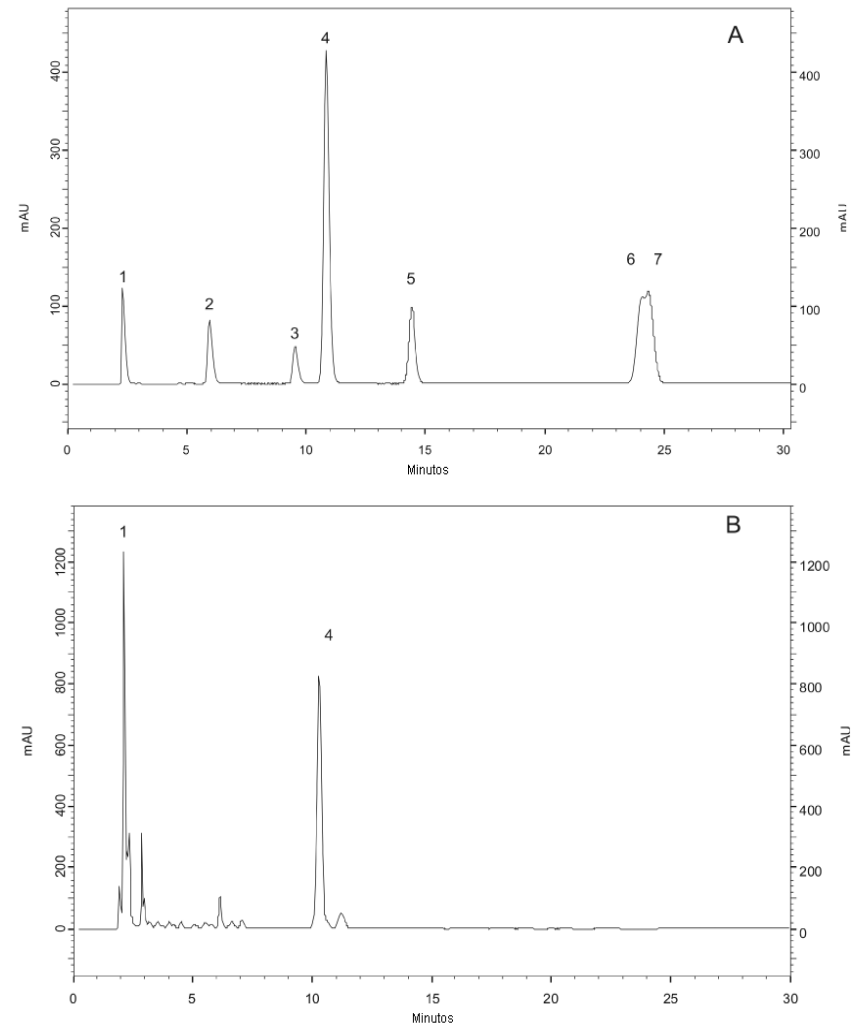

Figura 2. Separação cromatográfica obtida com monitoramento em 225 nm: (A) calibrador contendo $C R^{1}(120 \mu \mathrm{g} / \mathrm{mL}) ; F G^{2}(50 \mu \mathrm{g} / \mathrm{mL}) ; A M^{3}(50$ $\mu \mathrm{g} / \mathrm{mL}) ; A H^{4}(100 \mu \mathrm{g} / \mathrm{mL}) ; o-M H^{5}(50 \mu \mathrm{g} / \mathrm{mL}) ; p-M H^{6}$ e $m-M H^{7}(50 \mu g / m L$ e $50 \mu \mathrm{g} / \mathrm{mL}) ;(B)$ amostra de urina $C R^{1}(1.698 \mu \mathrm{g} / \mathrm{mL}) ; A H^{4}(1768 \mu \mathrm{g} / \mathrm{mL}$; $1,04 \mathrm{~g} / \mathrm{g}$ creatinina)

calibração obtidas com calibradores aquosos. Os valores calculados encontraram-se na faixa de 96 a $108 \%$ das concentrações adicionadas, demonstrando que o efeito da matriz apresentou um pequeno impacto na performance analítica do método. A precisão intra e inter-ensaios esteve entre 0,23 a 4,89\%, demonstrando a elevada repetibilidade do método, especialmente devida à preparação de amostra simples. A exatidão foi determinada entre 95 e 106\%, também dentro dos critérios de aceitação para métodos bioanalíticos preconizados por Shah et al.. ${ }^{13}$ Considerando o propósito da metodologia proposta neste estudo, focada no monitoramento biológico e com valores limiares definidos, os limites de detecção e quantificação são bastante inferiores aos IBMP.

Na Tabela 3 são apresentados os intervalos das concentrações obtidas através das análises das amostras de urina dos indivíduos expostos ocupacionalmente ao tolueno, xileno e estireno, utilizando a metodologia desenvolvida. Dentre as amostras testadas, apenas uma apresentou valor acima do IBMP, com concentração de AH de 3,18 g/g CR. Para os demais indicadores de exposição, os valores foram abaixo do valor de referência.

Uma vantagem do método desenvolvido é a determinação simultânea de CR, além dos bioindicadores de exposição ácido fenilglioxílico, ácido mandélico, ácido hipúrico e ácido metil-hipúrico. Cabe destacar que a NR-7 estabelece valores referenciais para estes bioindicadores relacionados à concentração de creatinina urinária, sendo indispensável a quantificação de CR nas análises de finalidade ocupacional, no Brasil. Nos métodos relatados na literatura, esta determinação é realizada em paralelo, através de espectrofotometria na região do visível. Desta forma, a incorporação da determinação 
Tabela 2. Parâmetros de validação do método

\begin{tabular}{|c|c|c|c|c|c|c|c|c|}
\hline Analito & $\begin{array}{c}\text { Concentração } \\
(\mu \mathrm{g} / \mathrm{mL})\end{array}$ & $\begin{array}{l}\text { Intra-dias } \\
\text { (cv \%) }\end{array}$ & $\begin{array}{c}\text { Inter-dias } \\
\text { (cv \%) }\end{array}$ & Exatidão (\%) & Equação & $\mathrm{r}^{2}$ & $\mathrm{LD}(\mu \mathrm{g} / \mathrm{mL})$ & $\mathrm{LQ}(\mu \mathrm{g} / \mathrm{mL})$ \\
\hline \multirow{3}{*}{$\mathrm{AH}$} & 600 & 0,84 & 0,69 & 106 & \multirow{3}{*}{$\begin{aligned} y= & 6429,79 x+ \\
& 162063\end{aligned}$} & \multirow{3}{*}{0,9988} & \multirow{3}{*}{0,06} & \multirow{3}{*}{0,18} \\
\hline & 1800 & 1,20 & 0,60 & 106 & & & & \\
\hline & 2800 & 2,05 & 0,99 & 106 & & & & \\
\hline \multirow{3}{*}{$o-\mathrm{MH}$} & 600 & 2,43 & 1,61 & 101 & \multirow{3}{*}{$\begin{array}{c}y=3123,72 x+ \\
93397\end{array}$} & \multirow{3}{*}{0,9950} & \multirow{3}{*}{0,21} & \multirow{3}{*}{0,69} \\
\hline & 1600 & 1,85 & 1,18 & 103 & & & & \\
\hline & 2400 & 0,00 & 1,26 & 103 & & & & \\
\hline \multirow{3}{*}{$m, p$-AMHs } & 600 & 2,23 & 1,55 & 103 & \multirow{3}{*}{$\begin{array}{c}y=5233,65 x+ \\
87194\end{array}$} & \multirow{3}{*}{0,9982} & \multirow{3}{*}{0,21} & \multirow{3}{*}{0,68} \\
\hline & 1600 & 1,72 & 1,17 & 101 & & & & \\
\hline & 2400 & 1,65 & 1,41 & 101 & & & & \\
\hline \multirow{3}{*}{$\mathrm{AM}$} & 270 & 0,42 & 0,32 & 99 & \multirow{3}{*}{$\begin{array}{c}y=1490,55 x+ \\
13429\end{array}$} & \multirow{3}{*}{0,9970} & \multirow{3}{*}{0,24} & \multirow{3}{*}{0,79} \\
\hline & 630 & 0,45 & 0,23 & 103 & & & & \\
\hline & 1260 & 0,25 & 0,21 & 97 & & & & \\
\hline \multirow{3}{*}{ AFG } & 540 & 1,95 & 1,47 & 103 & \multirow{3}{*}{$\begin{array}{c}y=2583,16 x+ \\
132464\end{array}$} & \multirow{3}{*}{0,9906} & \multirow{3}{*}{0,14} & \multirow{3}{*}{0,46} \\
\hline & 1620 & 1,12 & 0,99 & 98 & & & & \\
\hline & 2520 & 1,35 & 0,85 & 97 & & & & \\
\hline \multirow{3}{*}{ CR } & 33 & 4,89 & 3,36 & 99 & \multirow{3}{*}{$\begin{array}{c}y=3621,37 x+ \\
14246\end{array}$} & \multirow{3}{*}{0,9986} & \multirow{3}{*}{0,09} & \multirow{3}{*}{0,33} \\
\hline & 266 & 1,76 & 1,61 & 98 & & & & \\
\hline & 720 & 1,08 & 1,12 & 95 & & & & \\
\hline
\end{tabular}

LD: limite de detecção; LQ: limite de quantificação

Tabela 3. Valores encontrados nas análises de amostras de urina de indivíduos expostos ocupacionalmente ao tolueno, xileno e estireno

\begin{tabular}{lcc}
\hline Biomarcador & $\begin{array}{c}\text { Número } \\
\text { indivíduos }\end{array}$ & $\begin{array}{c}\text { Concentração }(\mathrm{g} / \mathrm{g} \\
\text { creatinina) }\end{array}$ \\
\hline Ácido mandélico & 15 & ild $-0,08$ \\
Ácido fenil-glioxílico & 15 & ild $-0,05$ \\
Ácido hipúrico & 15 & $0,35-3,18$ \\
Ácidos metil-hipúricos & 15 & ild $-0,07$ \\
\hline
\end{tabular}

ild: inferior ao limite detecção

da creatinina no procedimento da determinação dos indicadores de exposição ao tolueno, xileno e estireno representa um considerável ganho de tempo e de economia em recursos laboratoriais.

\section{CONCLUSÃO}

Um método para a determinação simultânea de creatinina, ácido fenilglioxílico, ácido mandélico, ácido hipúrico e ácido metil-hipúrico por CLAE-DAD foi desenvolvido e validado. A preparação das amostras foi simples e rápida. O método foi preciso e exato, com sensibilidade adequada para o monitoramento biológico através da determinação destas substâncias. O método foi aplicado no monitoramento biológico de trabalhadores expostos ocupacionalmente ao tolueno, xileno e estireno. A determinação da creatinina no mesmo procedimento analítico de doseamento de ácido fenilglioxílico, ácido mandélico, ácido hipúrico e ácido metil-hipúrico representa um importante ganho de tempo e economia de recursos.

\section{REFERÊNCIAS}

1. Ohashi, Y.; Mamiya, T.; Mitani, K.; Wang, B.; Takigawa, T.; Kira, S.; Kataoka, H.; Anal. Chim. Acta 2006, 566, 167.

2. Forster, L. M. K.;Tannhauser, M.; Tannhauser, S. L.; Rev. Saúde Pública 1994, 28, 167.

3. Miranda, C. R.; Dias, C. R.; Cad. Saúde Pública 2004, 20, 224.

4. Pereira, A. D.; Tratado de Segurança e Saúde Ocupacional Aspectos Técnicos e Jurídicos NR-7 a NR-1, LTR: São Paulo, 2005, vol. II

5. Bertoncello, L.; Monografia de Conclusão de Curso de Especialização, CEFAC, São Paulo, 1999.

6. http://www.mte.gov.br/legislacao/normas_regulamentadoras/nr_07.asp, acessada em Março 2007.

7. Laffon, B., Lema, M.; Mendez ,J.; J. Chromatogr., B: Anal. Technol. Biomed. Life Sci. 2001, 753, 385.

8. Kongtip, P.; Vararussami, J.; Pruktharathikul, V.; J. Chromatogr., B: Anal. Technol. Biomed. Life Sci. 2001, 751,199.

9. Prieto, M. J.; Marhuenda, D.; Cardona, A. J.; Anal. Toxicol. 2002, 26, 23

10. Chakroun, R.; Hedhili, A.; Faidi, F.; Nouaigui, H.; Laiba, M. B.; Anal. Lett. 2006, 39, 83.

11. Ogata, M.; Taguchi, T.; Int. Arch. Occup. Environ. Health 1988, 61, 131.

12. Poggi, G.; Giusiani, M.; Palagi, U.; Paggiaro, P. L.; Loi, A. M.; Dazzi, F.; Siclari, C.; Baschieri, L.; Int. Arch. Occup. Environ. Health 1982, 50, 25.

13. Shah, V. P.; Midha, K. K.; Findlay, J. W.; Hill, H. M.; Hulse, J. D.; McGilveray, I. J.; McKay, G.; Miller, K. J.; Patnaik, R. N.; Powell, M. L.; Tonelli, A.; Viswanathan, C. T.; Yacobi, A.; Pharm. Res. 2000, 17, 1551. 